\title{
Closing the income-achievement gap? Experimental evidence from high-dosage tutoring in Dutch primary education
}

\author{
Joppe de Ree* \\ Mario A. Maggioni ${ }^{\dagger}$ \\ Bowen Paulle \\ Domenico Rossignoli ${ }^{\S}$ \\ Nienke Ruijs \\ Dawid Walentek ${ }^{\|}$
}

\begin{abstract}
We present experimental evidence on a high-dosage tutoring (HDT) program implemented in three primary schools in a low-income neighborhood in the Netherlands. We document treatment effects of 0.28 national population standard deviations in math achievement scores $(p<0.01)$ after one school year. These treatment effects are sizable and can account for roughly $40 \%$ of the math achievement gap between low-income and high-income students in the Netherlands. As most of the evidence on intensive tutoring programs draws on research from low-income settings in the US, our findings show that $(i$.) HDT programs can be successfully built from the ground up and exported to different institutional settings while maintaining meaningful effect sizes, and, (ii.) existing income-achievement gaps can be substantially reduced with practical and scalable interventions like HDT.
\end{abstract}

*Erasmus University Rotterdam. Corresponding author: joppederee@gmail.com. The authors thank Dinand Webbink for helpful comments and discussions, Isabel Speelman and Shelby Sissing for excellent research assistance, and Shelby Sissing for editorial support. From his role at te University of Amsterdam, one of the authors of this paper (Bowen Paulle) advocated for, and advized on the implementation of the intervention that is investigated in this paper.

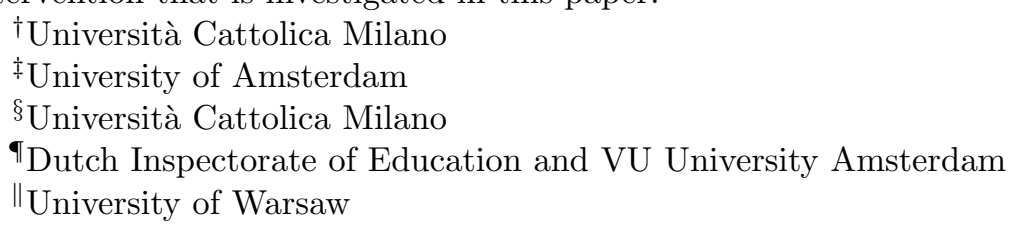




\section{Introduction}

Despite decades of comparatively generous welfare state policies in the Netherlands, meaningful income-achievement gaps in academic performance persist and may be widening 11 Previous policies to address these inequalities have developed largely in a piecemeal fashion and have not been able to structurally reduce these gaps. Recently however, high-dosage tutoring (HDT) programs have been suggested as a promising way forward to help reducing inequalities in educational outcomes at scale $2^{2}$ The popularity of HDT programs might be explained by the combination of two factors: documented sizable treatment effects and a relatively uncomplicated method of delivery $\left[^{3}\right.$ The latter would facilitate scaling up and exporting the program to other environments, with new and relatively inexperienced people responsible for service delivery.

The evidence base for high-dosage tutoring programs, however, draws mainly on research from low-income settings in the US. It is not clear how to value these estimates for policymaking decisions in the Netherlands, or in other similar environments. We expect that at least two factors play a role here. First, comparatively high levels of income redistribution and related welfare state provisions exist in the Netherlands, which primarily benefit low-income families.$^{4}$ In the presence of diminishing returns, one might expect a reduction in the effect sizes in this context.5 Second, scaling up, or even exporting otherwise

\footnotetext{
${ }^{1}$ See for example Borghans, Diris, and Schils (2018) [in Dutch] and Dutch Inspectorate of Education (2019) [in Dutch]. While achievement gaps may have widened somewhat in the past decade or so, the "big picture" is that achievements gaps between low-income and high-income students are sizable and quite persistent. These patterns are not unique to the Netherlands and can be found all over the world (e.g. Reardon (2011)).

${ }^{2}$ Intensive, or high-dosage tutoring programs provide tutoring for one hour each day, for multiple days a week, for an entire school year. Typically small group personalized tutoring with a student-to-tutor ratio of around 2-to-1.

${ }^{3}$ See e.g. Guryan et al. (2021) and Kraft (2015), as well as Nickow, Oreopoulos, and Quan (2020) and Pellegrini et al. (2021) for overviews of experimental research. In addition to the evidence, policymakers in quite a few countries have picked up on tutoring programs in their efforts to reduce losses due to the COVID-19 pandemic (e.g. https://nationaltutoring.org.uk/faqs).

${ }^{4}$ See e.g. Alesina and Glaeser (2005) who document differences in service provision between European welfare states and the US.

${ }^{5}$ See e.g. Jackson, Johnson, and Persico (2016) for evidence on the importance of diminishing returns to
} 
successful programs to different contexts tends to reduce effect sizes, because high-quality implementation cannot be maintained consistently.

To investigate the feasibility of substantially reducing the achievement gap between low-income and high-income families through scalable interventions, we cooperated with funders, service providers and schools in an effort to implement a high-dosage math tutoring (HDT) program in a low-income neighborhood in the Netherlands. The HDT program was modeled after the successful Match Education program ${ }^{6}$ which was subsequently developed further by Saga Education?7. Tutoring is delivered in small teams of one tutor and two students, who would remain together for the duration of the program. The program took place during regular school hours, for 1 class hour each day, for 4 days a week, for an entire school year 8 Primary school 5 th graders were the main target group for the intervention ${ }^{9}$

To evaluate the effects of the HDT program we used a randomized controlled trial (RCT). The RCT ran for 3 consecutive school years, from 2015/16 to 2017/18. On average, across three cohorts, we document one-year treatment effects of 0.28 national population standard deviations $(p<0.01)$. The effects are qualitatively similar to earlier findings from the US, indicating that exporting the program to a new context did not meaningfully reduce effect sizes. We do not find evidence for heterogeneous effects across the baseline achievement distribution, indicating that both high and low achievers benefited. We also do not find evidence for (positive or negative) effects on reading comprehension.

Our two main contributions are the following. First, we show that the income-achievement gap can be significantly reduced by HDT programs, even in welfare states like the Nether-

school spending. In addition Jackson (2018) shows evidence on the effects of school funding and Duncan, Magnuson, and Votruba-Drza (2017) for some evidence on the effects of household poverty on student achievement.

${ }^{6}$ See for information on the Match Education program (https://www.matcheducation.org/export/ prior-projects/district-parnerships/) as well as Fryer Jr. (2014) who analyses best practices of charter schools in the US, including high-dosage tutoring.

7 https://www.sagaeducation.org/our-story

${ }^{8}$ The Dutch program provides tutoring for four days a week, while the original Match model provides tutoring on all 5 school days.

${ }^{9}$ In Dutch groep 7 leerlingen. 
lands with comparatively modest, yet very persistent, income achievement gaps. An application of our treatment effects to the broader population of low-income Dutch students suggests that the math achievement gap between low-income students (the 10th percentile of the parental income distribution) and students at the median of the parental income distribution can be fully eliminated. This finding presents a powerful image of what the results might be if HDT can be further scaled up. That is, our findings suggest that substantial reductions in inequalities in outcomes can be achieved. We think this result may be powerful enough to influence beliefs and aspirations of policymakers (and voters) in the Netherlands as well as in other similar institutional settings. Research has suggested that preferences for (income) redistribution can be influenced by differences in beliefs. Alesina and Angeletos (2005) for example argue that preferences for redistribution between the US and Europe are influenced by differences in beliefs about the drivers of (income) inequality.

Second, we demonstrate that HDT can be exported to very different institutional settings while maintaining meaningful effect sizes. To be sure, the project examined here, implements HDT at pilot scale. But the fact that the program was successfully built up from scratch underscores the scalability of HDT programs 10 One key feature of HDT programs is that it runs largely independently of regular school operations so that it does not require much behavioral change from the school personnel, e.g. the classroom teachers. Kraft (2020) argues that "the challenge posed by taking programs to scale is largely proportional to the degree of behavioral change required to implement a program". Other approaches meant to boost achievement, for example those focusing on improving teacher effectiveness, might not be nearly as easily exported or scaled up (see e.g. Jacob and Lefgren (2004)). The central importance of scalability also comes into view when considering the enormous tutoring projects that may soon be used in attempts to reverse achievement losses caused by the COVID-19 pandemic, see e.g. https://nationaltutoring.org.uk/faqs. These

\footnotetext{
${ }^{10}$ See also Davis et al. (2017) for a discussion on the economics of scale-up, and Kraft (2020) for arguments about the importance of scalability when assessing educational interventions.
} 
planned large scale interventions exemplify a belief in the scalability of tutoring programs and our research provides a useful reference for this ${ }^{11}$

The remainder of the paper is organized as follows. In Section 2 we introduce and describe the HDT intervention. In Section 3 we present the research design and in Section 4 we show and discuss our findings. Section 5 concludes and suggests areas for further research.

\section{High-dosage tutoring and the local context}

The HDT program was introduced in 2015/16 in all three primary schools in a low-income neighborhood in the Netherlands. The program was part of a broader effort to support children of low-income families. Median parental income of 6th graders in this neighborhood was at the 20th percentile nationally, and the spread of parental income roughly spans the bottom half of the national parental income distribution.

The Dutch HDT program was built from the ground up by schools, funders, service providers that had no prior experience with implementing this intervention ${ }^{13}$ In large part, the HDT model aimed at replicating the successful Saga Education program. Staff from Saga Education have also served as consultants on this project. Other than a temporary consulting grant, however, there was no formal relationship between the HDT provider for this project and Saga Education. The Saga Education program, as mentioned above, developed out of the Match Education HDT program and the Boston charter school movement. At the time of the development of the Dutch HDT program, existing Match/Saga

\footnotetext{
${ }^{11}$ Recent research has estimated the effects of school closures in the Netherlands at $8 \%$ of a standard deviation, up to $11 \%$ for disadvantaged youth (Engzell, Frey, and Verhagen 2020). Such losses can be addressed by the HDT model that we study in this paper. Catching up quickly might be important as some research finds long term effects of reduced time in school (Andrabi, Daniels, and Das 2020).

${ }^{12}$ Authors' calculations based on administrative data from Statistics Netherlands.

${ }^{13}$ As some stakeholders have expressed a desire to remain anonymous, we do not mention some of the local details of the HDT intervention.
} 
HDT programs were starting to show promising impacts in low-income settings in the US, particularly for young adolescents (e.g. Cook et al. (2014) and Fryer Jr. (2014) as well as based on preliminary findings from ongoing research projects). By now, the Saga Education program has been successfully RCT-tested multiple times in the US and efforts to scale up this program are currently underway (Guryan et al. 2021). The scaling up process is also being interrogated in its own right 14

The development of HDT programs was informed by the recognition that intensive individualized instruction is highly effective. Bloom (1984) describes a test setup in which students in a 1-on-1 tutoring regime outperformed a control group in a regular classroom by 2 standard deviations of a control group. A key aspect here is that tutors can specifically target instruction to the achievement level of each child. Bloom observed that individualized instruction was highly effective, but also very costly. He raised the question of whether (and how) to devise a teaching model that could be as effective as 1-on-1 tutoring, but less expensive to implement. This quest has become known as Bloom's "2-sigma problem", referring to the 2 standard deviation treatment effects.

The HDT model takes elements of individualized instruction, but it limits costs by providing tutoring for 50-minute sessions each day and relying on paraprofessional tutors (rather than fully certified teachers). The program lasted a full school year for each selected student and was implemented 4 days a week (excluding Wednesdays). In the beginning of the school year, small groups or teams were (nonrandomly) formed, consisting of 2 students and 1 tutor. These teams were formed based on perceived fit and, in part, on math achievement levels at baseline. Students and tutors are meant to remain together in such teams for the duration of the program. This stability is meant to foster trust-building, creating an environment in which students feel comfortable making mistakes and trying out new things.

\footnotetext{
${ }^{14}$ https://www.socialscienceregistry .org/trials/2258/history/66461
} 
In this setting, successes are observed, acknowledged and explicitly celebrated. The HDT model, therefore, has a strong focus on the socioemotional aspects of learning. Similar mentoring relationships have been found to boost socioemotional skills (e.g. Kosse et al. (2020)). Socioemotional, or noncognitive, skills, like confidence or motivation, are likely important factors in explaining successes in school and in life more generally (Heckman, Stixrud, and Urzua 2006). The tutors also involved parents by contacting them about once every two weeks.

Delivering small group instruction (or tutoring) requires less skills and training on the part of the instructor, than delivering regular classroom instruction. Consequently, more people (at lower wage rates) would qualify for a tutoring job. People can also be a tutor temporarily without giving up on longer-term (career) plans, e.g. during a "gap year" after finishing a BA degree. The tutoring sessions took place in separate classrooms, and a site director (or team leader) was meant to be present (at least) $80 \%$ of the time to support the process. The site directors of this program received training from Saga Education and the experimental sites were visited by Saga Education staff a number of times over the years.

Some aspects of the original Saga Education model were changed in collaboration with the schools and other stakeholders. First, the Dutch model provided tutoring for 4 days per week, rather than the original 5 days per week. Second, the tutoring program did not always provide individualized lesson planning, but during two out of the four days a week of tutoring followed the school's curriculum. Third, half of the weekly tutoring sessions (two out of four) occurred during hours dedicated to regular classroom math instruction. It was however agreed that the classroom teachers would only introduce new concepts when all students (treated and control) were present in class. Overall, the HDT model we study in this paper is somewhat less intense, or less high-dosage, than the original Saga Education model 15

\footnotetext{
${ }^{15}$ The original Saga Education model was fully personalized and five days, rather than four days a week.
} 
The main target group of the intervention are primary school 5th graders. A team of 6 tutors (and a site director) were responsible for delivering the program to the treatment group 16 With 6 tutors and 2 students per tutor, this implies that there are 12 seats available in each tutoring session. As there were not always enough eligible 5th grade students, the 12 available seats were supplemented with randomly selected 4th graders. This has some consequences for the way we interpret the RCT design (see Section 3).

\section{The experimental design}

The RCT ran for three consecutive school years and applied to three cohorts. The primary target for the intervention were all primary school 5th graders in the three participating schools. Students were randomly assigned to treatment using a block-randomization procedure. For all cohorts we blocked by classroom. For the third cohort, we also blocked by baseline (4th grade) math scores. Table 1 shows the size of the 5 th grade experimental sample, by classroom and by school year. Table 1 also shows that the 5 th grade treatment groups did not always fill the 12 available seats. To not waste valuable tutoring time, randomly selected 4 th graders were added to fill the groups. Table 2 shows the size of the 4th grade experimental sample, by class and by school.

\footnotetext{
${ }^{16}$ As the project continued, the number of students that participated with the HDT program increased each year. Consequently, additional tutors were hired.
} 
Table 1: Size of the 5th grade experimental sample, by year of implementation, and by treatment and control groups

\begin{tabular}{|c|c|c|c|c|c|c|}
\hline & $(1)$ & $(2)$ & $(3)$ & (4) & $(5)$ & $(6)$ \\
\hline & \multicolumn{2}{|c|}{ Year 2015/16 } & \multicolumn{2}{|c|}{ Year 2016/17 } & \multicolumn{2}{|c|}{ Year 2017/18 } \\
\hline & $\mathrm{T}$ & $\mathrm{C}$ & $\mathrm{T}$ & $\mathrm{C}$ & $\mathrm{T}$ & $\mathrm{C}$ \\
\hline School 15 & 11 & 11 & 12 & 11 & 12 & 12 \\
\hline School 2 5-a & 8 & 8 & 8 & 9 & 10 & 12 \\
\hline School 2 5-b & 10 & 10 & 9 & 9 & 4 & 5 \\
\hline School 3 5-a & 12 & 13 & 9 & 9 & 8 & 7 \\
\hline School 3 5-c & 9 & 9 & 6 & 7 & 2 & 3 \\
\hline Total 5 & 50 & 51 & 44 & 45 & 36 & 39 \\
\hline
\end{tabular}

Notes. Sample size for the 5 th grade experimental sample decreases with time, as more 4 th graders were added to the experimental sample to supplement the tutor groups. As a result, fewer 5 th graders were eligible for randomization in round 3 than in round 1.

Table 2: Size of the 4th grade experimental sample, by year of implementation, by treatment and control groups

\begin{tabular}{|c|c|c|c|c|c|c|}
\hline & (1) & $(2)$ & $(3)$ & $(4)$ & $(5)$ & $(6)$ \\
\hline & \multicolumn{2}{|c|}{ Year 2015/16 } & \multicolumn{2}{|c|}{ Year 2016/17 } & \multicolumn{2}{|c|}{ Year 2017/18 } \\
\hline & $\mathrm{T}$ & $\mathrm{C}$ & $\mathrm{T}$ & $\mathrm{C}$ & $\mathrm{T}$ & $\mathrm{C}$ \\
\hline School 14 & 1 & 22 & & & & \\
\hline School 2 4-a & 4 & 17 & 4 & 18 & & \\
\hline School 2 4-b & 2 & 18 & 3 & 17 & 9 & 9 \\
\hline School 3 4-a & & & 3 & 17 & 4 & 4 \\
\hline School 3 4-c & 3 & 12 & 6 & 5 & 9 & 9 \\
\hline Total 4 & 10 & 69 & 16 & 57 & 22 & 22 \\
\hline
\end{tabular}

Notes. Sample size for the 4th grade experimental sample increases with time, as more 4 th graders were added to the experimental sample to supplement the tutor groups.

It was agreed with schools and other stakeholders that students of each cohort would 
only receive tutoring once, in one school year. Therefore, students who were once randomly assigned to treatment were no longer considered any subsequent year. Because 4th graders were added to supplement the empty seats, the number of eligible 5th graders - Those who were not previously assigned to treatment in 4th grade - progressively decreased.

A second consequence of the agreement was that all students who were not randomly assigned to treatment in 4th or in 5th grade, would automatically receive tutoring in 6th grade. Therefore, the experimental design can be viewed as a randomized rollout (or phasein) design, in which the timing of receiving tutoring (not the receiving of the tutoring per se) is determined by chance. ${ }^{17}$ In Section 4.1 we discuss the results based on the rollout design in more detail.

The main analysis focuses on the 5th grade experimental sample, for which we obtain precise estimates of the treatment effects. We also report on the 4 th grade results, but the treatment effects measured of this group are less precisely estimated. As outcome measures we primarily use comparable standardized tests, developed by test developer Cito, used by almost all primary schools in the Netherlands 18 Primary schools rely on these tests for monitoring each student's progression in math and literacy, and for comparison to the national distribution of achievement of each age group. Students are typically tested twice a year for math and literacy (reading comprehension, etc.). Semester-to-semester performance on these tests are used as a basis for secondary school track assignment at the end of primary education. The tests are, therefore, high stakes. In Appendix A we show baseline summary statistics, including balance tests. The tables show that treatment and control students are similar on observable baseline characteristics.

In the analysis we standardized test scores with respect to the (estimated) national means and (estimated) national standard deviations for each grade-semester. That is, we

\footnotetext{
${ }^{17}$ As all students receive tutoring at one point, we cannot use the design to study long term effects. The design would in principle allow for studying the long term effects of the timing of receiving tutoring. However, we think that our design will not be sufficiently powerful to detect reasonable effect sizes.

${ }^{18}$ https://cito.com/student-tracking-systems
} 
scale the test scores $Y_{\text {igs }}$, for student $i$ in grade $g$ in semester $s$, as follows:

$$
y_{i g s}=\frac{Y_{i g s}-\mu_{g s}}{S D_{g s}}
$$

The test developer provides survey estimates of national mean $\mu_{g s}$ and quintile cutoffs for each grade-semester. Based on the quintile cutoffs we estimate $S D_{g s}$ by dividing the distance between the 20 th and the 80 th percentile by 1.683 , which is the distance measured in standard deviation units between the 20th and the 80th percentile of a normal distribution.

The treatment effects are estimated using the following linear regression model:

$$
y_{i g s}=\alpha+\beta T_{i}+\gamma_{01} y_{i g-1,1}+\gamma_{02} y_{i g-1,2}+\sum_{k=1}^{K} I\left(\text { block }_{k}=1\right)+u_{i g s}
$$

where $T_{i}$ is a dummy variable that is 1 for students randomly assigned to treatment, and 0 for control. $y_{i g-1,1}$ and $y_{i g-1,2}$ are baseline scores, measured in the 1st and 2nd semester of the school year prior to randomization. If one of the two baseline scores is not observed, we impute the missing score with a prediction out of the nonmissing baseline score, or otherwise out of scores that were observed two years prior to randomization. For prediction we use a simple linear OLS regression model on the nonmissing data. If for any student no prior test score data is observed, we set both baseline scores to zero and include an additional dummy variable in the regression model that is 1 for observations with unobserved baseline data, and 0 otherwise ${ }^{19}$ For precision it is important to control for baseline values. The results however are robust to variations in the exact way of controlling for baseline values.

\footnotetext{
${ }^{19}$ See e.g. De Ree et al. (2018) who deal with missing baseline data in the same way.
} 


\section{Results}

Table 3 presents the estimated treatment effects on the math tests for the 5th and 4th grade experimental samples. Because we do not measure any clear differences between rounds we pool the three rounds of data. In Appendix B we present results by year of implementation. The first row presents estimated treatment effects for the 5th grade experimental sample. The effects are precisely estimated with $t$ statistics greater than 4 (in column [2]). We find treatment effects of 0.25 population standard deviations after the first semester, and 0.28 population standard deviations after one school year of HDT. The results for the 4th grade sample are less precisely estimated, but point in the same direction. In Appendix C we show results measured in control group standard deviation units (i.e. Glass' $\Delta$ ). The treatment effect estimates expressed in terms of control group standard deviations are (surprisingly) somewhat smaller (0.25 standard deviations after a year) than those expressed in national population standard deviations. Given the focus of our paper, we prefer to report results in terms of national population standard deviations as it allows for a more direct comparison to policy objectives. 
Table 3: Treatment effects on math scores, measured in national population standard deviation units

\begin{tabular}{ccc}
\hline \hline & $(1)$ & $(2)$ \\
& half-year treatment effect & one year treatment effect \\
\cline { 2 - 3 } pooled 5th grade cohort & $0.25^{* * *}$ & $0.28^{* * *}$ \\
& $(0.07)$ & $(0.06)$ \\
& {$[265]$} & {$[265]$} \\
& $<255>$ & $<251>$ \\
pooled 4th grade cohort & $|246|$ & $|242|$ \\
& 0.08 & $0.26^{*}$ \\
& $(0.11)$ & $(0.15)$ \\
& {$[233]$} & {$[233]$} \\
& $<222>$ & $<219>$ \\
& $|211|$ & $|208|$ \\
\hline \hline
\end{tabular}

Notes. ${ }^{* * *},{ }^{* *}, *$ indicate statistical significance at the 1, 5, and $10 \%$ level. Estimated treatment effects are measured in national population standard deviation units. Heteroskedasticity robust standard errors in parentheses. All regressions include sampling block (or stratum) fixed effects (the level at which randomization was done) and baseline test score values. The total size of the experimental sample between [..], the size of the sample used to produce the estimates between $\langle\ldots\rangle$, the size of the sample which has observed baseline test scores between |..|. Missing baseline test scores are set to zero and a dummy variable is included in the regression model that is 1 for observations for which baseline tests are missing.

Table 4 shows results based on an alternative math outcome, the math speed test. The speed test is a quick test in which students provide as many correct answers as they can within a specific time frame (4 minutes). On this test, we also estimate highly significant treatment effects measured in control group standard deviation units. 
Table 4: Treatment effects on speed test math (Tempo Toets Rekenen), measured in control group standard deviation units

\begin{tabular}{ccc}
\hline \hline & $(1)$ & $(2)$ \\
& half-year treatment effect & one year treatment effect \\
\cline { 2 - 3 } pooled 5th grade cohort & $0.17^{* *}$ & $0.32^{* * *}$ \\
& $(0.09)$ & $(0.09)$ \\
& {$[265]$} & {$[265]$} \\
& $<256>$ & $<232>$ \\
pooled 4th grade cohort & $|188|$ & $|166|$ \\
& 0.27 & $0.56^{* * *}$ \\
& $(0.18)$ & $(0.20)$ \\
& {$[233]$} & {$[233]$} \\
& $<204>$ & $<223>$ \\
\hline \hline
\end{tabular}

Notes. ${ }^{* * *},{ }^{* *}, *$ indicate statistical significance at the 1, 5, and $10 \%$ level. Estimated treatment effects are measured in control group standard deviation units. Heteroskedasticity robust standard errors in parentheses. All regressions include sampling block (or stratum) fixed effects (the level at which randomization was done) and baseline test score values. The total size of the experimental sample between [...], the size of the sample used to produce the estimates between $\langle.$.$\rangle , the size of the sample which has observed baseline$ test scores between |..|. Missing baseline test scores are set to zero, and a dummy variable is included that is 1 for observations for which baseline tests are missing.

In Table 5 we do not find statistically significant treatment effects for reading comprehension. While point estimates are negative, they do not suggest strong evidence for negative spillovers. Future research could pool data from multiple experiments to increase power to detect potential unintentional effects. 
Table 5: Treatment effects on reading comprehension scores, measured in national population standard deviation units

\begin{tabular}{ccc}
\hline \hline & $(1)$ & $(2)$ \\
& & \\
half-year treatment effect & one year treatment effect \\
\cline { 2 - 3 } pooled 5th grade cohort & -0.07 & -0.06 \\
& $(0.10)$ & $(0.11)$ \\
& {$[265]$} & {$[265]$} \\
& $<256>$ & $<222>$ \\
pooled 4th grade cohort & $|247|$ & $|215|$ \\
& -0.07 & -0.09 \\
& $(0.11)$ & $(0.12)$ \\
& {$[233]$} & {$[233]$} \\
& $<224>$ & $<222>$ \\
& $|213|$ & $|211|$ \\
\hline \hline
\end{tabular}

Notes. ${ }^{* * *},{ }^{* *}, *$ indicate statistical significance at the 1, 5, and $10 \%$ level. Estimated treatment effects are measured in national population standard deviation units. Heteroskedasticity robust standard errors in parentheses. All regressions include sampling block (or stratum) fixed effects (the level at which randomization was done) and baseline test score values. The total size of the experimental sample between [..], the size of the sample used to produce the estimates between $\langle\ldots\rangle$, the size of the sample which has observed baseline test scores between |... . Missing baseline test scores are set to zero, and a dummy variable is included that is 1 for observations for which baseline tests are missing.

At the mean, a treatment effect of 0.28 standard deviations corresponds to approximately one decile. Kraft (2020) qualifies such effects as large when compared to other educational interventions. However, when compared to experimental results of other tutoring interventions, our 0.28 might appear slightly weaker. For example, in a meta-analysis of 96 experimental evaluations of tutoring interventions, Nickow, Oreopoulos, and Quan (2020) estimate an average treatment effect of 0.37 standard deviations across field experiments. Note however that all but 2 of these 96 studies were based on populations in the US.

It is difficult however to precisely compare effect sizes across different populations and different tests. Naturally, effect sizes depend on the achievement spread in the reference 
population as well as on the breath of the content that is being tested. In this paper we report treatment effects against the achievement spread in the national distribution, measured on a broad standardized achievement test. This, we think, provides a relevant context for policymaking. Later on in this section we compare our treatment effects with other outcomes, such as the achievement gap between low-income and high-income students in the Netherlands.

In addition to these average effects, we are also interested in exploring further hypotheses. As we have not preselected low-achieving students, which is common for interventions aimed at reducing inequality, we have many high-achieving students in our sample. In Figure 1 we investigate the heterogeneity of the treatment effects with respect to baseline achievement. The curve is fitted using a local linear polynomial smoother 20 The curves are slightly downward sloping, indicating some regression to the mean due to noise in the test score measures. But overall, the figure does not indicate any heterogeneity in the treatment effect across the baseline achievement distribution. On the basis of a randomization inference procedure, we also cannot reject the null of a constant effect $\left.{ }^{21}\right|^{2}$ The results indicate that high-achievers also benefit from the additional support. In disadvantaged communities, high-ability students might face very particular challenges. They cannot always rely on their parents for help with math problems for example. An interesting avenue of further research would be to better understand the challenges faced by high potentials among the disadvantaged. It is plausible that investments in these high-potential, disadvantaged students yields important (economic) returns.

\footnotetext{
${ }^{20}$ Using the LPOLY command in Stata, using a bandwidth of 10 percentile points.

${ }^{21}$ The procedure to estimate the test statistic is explained in the notes below Figure 1

${ }^{22}$ Appendix D presents figures of the relationship between baseline and endline scores, separately for treatment and control, and separately by experimental cohort. We find consistently that treatment effects do not seem to differ much between high and low performance at baseline.
} 
Figure 1: Comparing gain scores in math between treatment [blue] and control [red], as a function of baseline math score percentiles

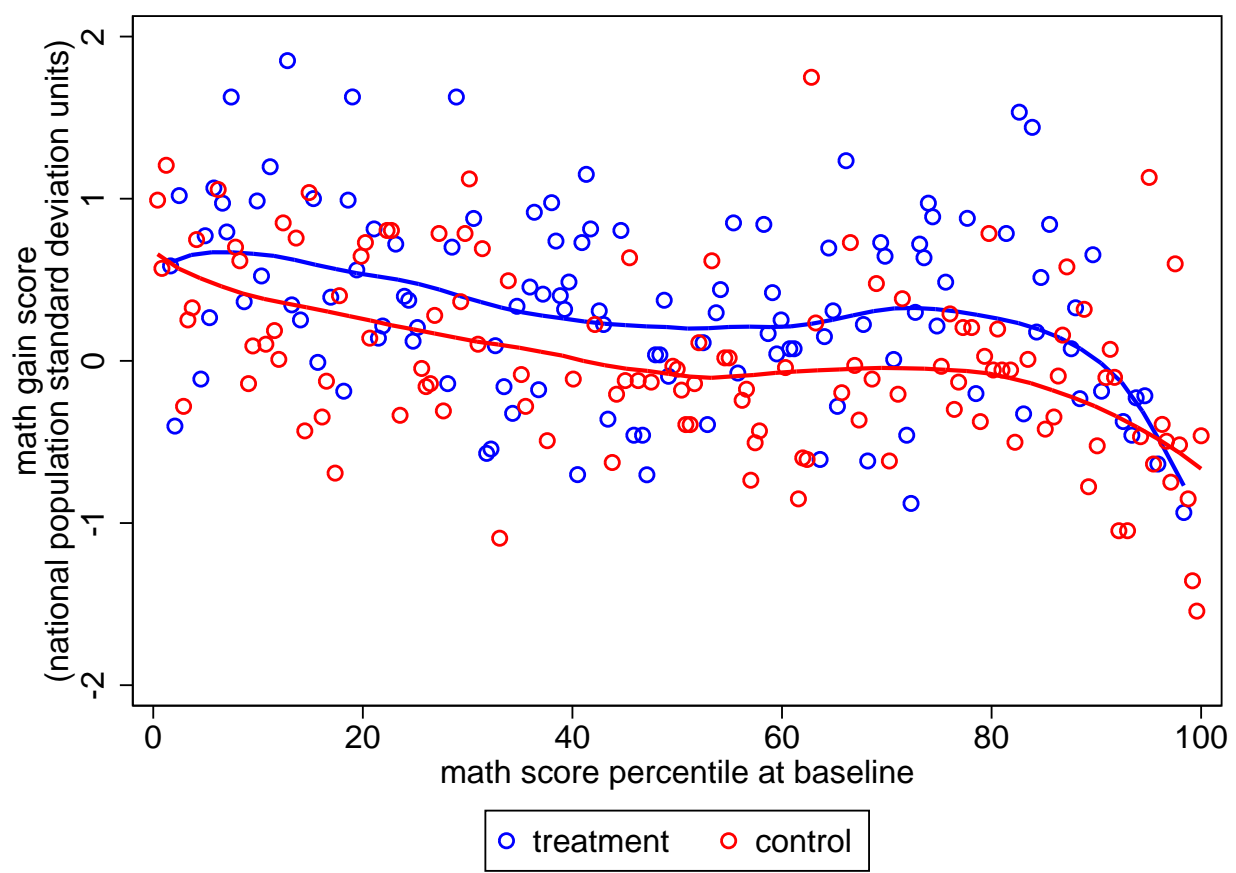

Notes: We test whether the treatment effect depends on the baseline outcome percentile using a randomization inference procedure. We first calculate the test statistic of interest $\sqrt{\sum_{p}(\tau(p)-\bar{\tau}(p))^{2}}$, which is the square root of the mean squared difference between the percentile specific estimated treatment effect and the (unweighted) mean. To assess the extremity of this quantity in the data, we redraw treatment assignment 5,000 times (in the same way as original treatment assignment was drawn) and calculate the same root mean squared error as described above. An evaluation of the test statistic in the distribution of 5,000 pseudo test statistics, indicates a $p$-value of 0.41 . Hence, we cannot reject the null that the treatment effect is independent of initial baseline achievement.

The HDT program we evaluate in this paper aimed at improving opportunities of children growing up in low-income, disadvantaged communities. It makes sense therefore to evaluate the effects of the HDT program in this context. Based on administrative data on all primary students in the Netherlands and their parents, we present the relationship between average standardized math achievement scores (based on the [Cito] end-ofprimary-education test) and parental income in Figure $\left.2\right|^{23}$ The figure presents a familiar

\footnotetext{
${ }^{23}$ We standardized test scores by subtracting the population mean and dividing by the standard deviation
} 
pattern: low-income students trail high-income students by a significant margin. The difference in achievement between students at the 10th percentile and the 90th percentile of the parental income distribution is 0.75 national population standard deviations. The estimated achievement gaps in the Netherlands appear only moderately less pronounced than similar estimates for the US24, despite the sizable differences in the level of income redistribution between the US and the Netherlands 25

The dashed horizontal lines in Figure 2 mark the average math achievement scores for the 10th, 50th and 90th percentile of the parental income distribution. We find that the difference between the 10th and the 50th percentile is roughly 0.27 population level standard deviations, and roughly equal to the one-year treatment effects we have presented in Table 3. In other words, the treatment effect is very significant in context of reducing achievement inequalities in the Netherlands. The dashed purple curve shows what might happen to math achievement if we project the 0.28 treatment effect on a typical low income neighborhood (with the same parental distribution profile as our experimental site). The shift upward (from the solid purple curve to the dashed purple curve above) clearly indicates the potential influence of the HDT program for low-income communities.

in the population after adjusting for less than perfect reliability. See Appendix F for derivations, as well as (Reardon 2011) who applies similar adjustments. The Cito test consists of a math and literacy component. The test is widely known in the Netherlands and has been a key aspect of testing in Dutch primary education since the 1970s. However, from 2014/15 onwards other test providers could enter the market for these end-of-primary-education tests. As a consequence, many schools (particularly schools that tend to score below average) now use tests from different developers. As a consequences of this, comparing scores across time and between different income levels, for example, has become more difficult. We calculate the combined total of parental income before tax, by adding up father's and mother's income.

${ }^{24}$ See e.g. Reardon (2011) and Michelmore and Dynarski (2017).

${ }^{25}$ For example, about $80 \%$ of students at the 10 th percentile of the parental income distribution receive rent subsidies. Also around $60 \%$ of these students are so-called "weighted" students, for which primary schools receive extra funding (see e.g. Ladd and Fiske (2011) for a perspective on the Dutch model of primary school financing). We present these estimates based on administrative data in Appendix G. In addition to that, there is low-cost health care for all citizens and generally high-quality and freely accessible primary and secondary schooling throughout the Netherlands. While this support might contribute to reducing inequality in educational outcomes, income achievement gaps in the Netherlands seem persistent. For example, we find that the income achievement gaps have not changed at all between 2008/09 and 2014/15, the period for which we have comparable data. Borghans, Diris, and Schils (2018) also emphasize persistence in achievement gaps between low-income and high-income students based on a much longer time window. 
Figure 2: Relationship between average math scores at the end of primary education and parental income (in percentiles)

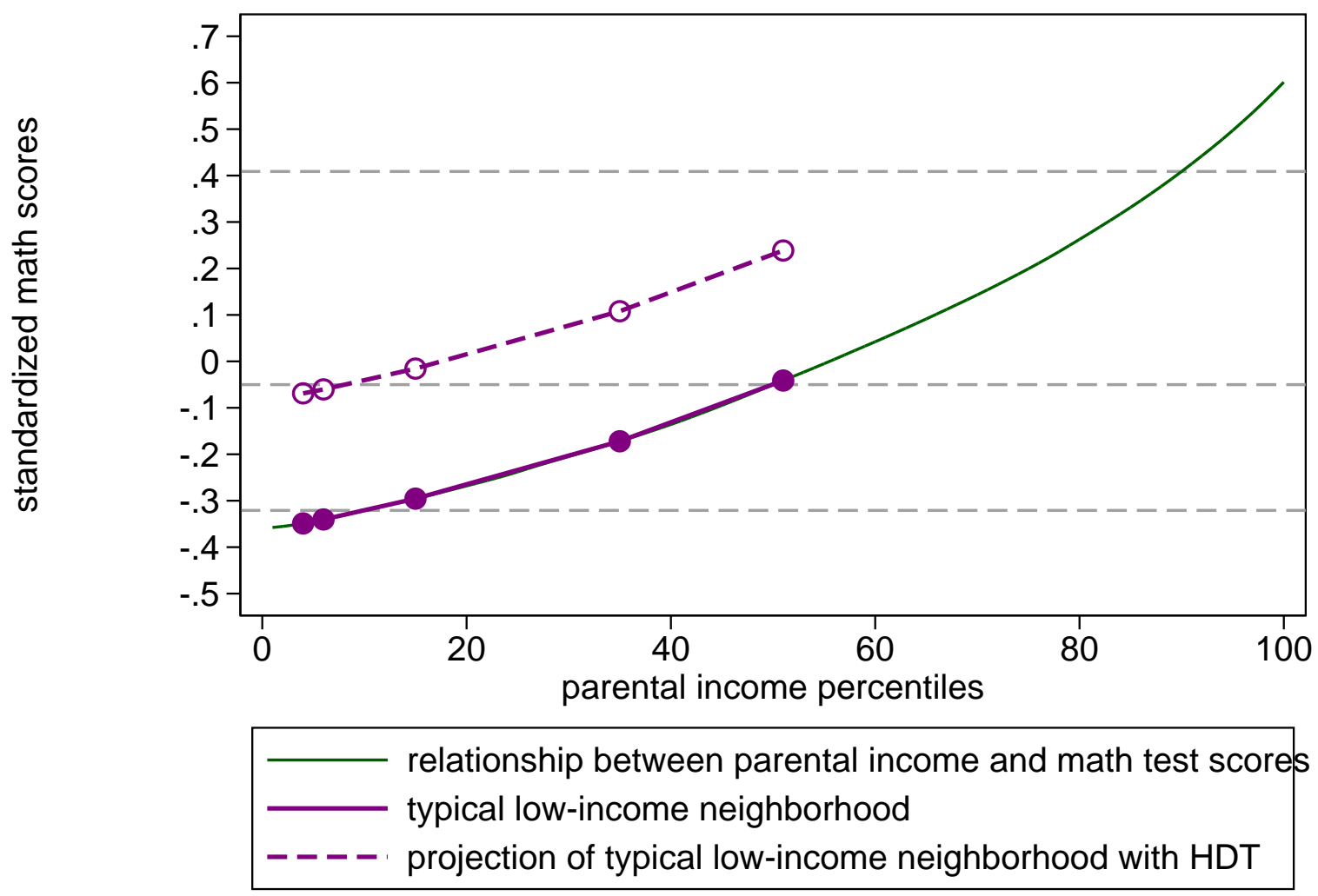

2013/14 school year

Notes: Green curve represents the relationship between parental income and the average math scores of 6th grade primary students. The vertical dotted lines indicate math scores associated with the 10th, 50th and 90th percentile of the parental income distribution. The distance between the scores associated with the 10th percentile and the median is roughly $0.27-0.29$ national population standard deviations (depending on the year of measurement) and roughly equal to the estimated one-year treatment effects of the HDT program. The solid purple curve represent a typical low-income neighborhood, where the dots represent the 10th, 25th, 50th, 75th and 90th percentiles of the neighborhood level parental income distribution. The dashed purple curve is a projection of math performance in this pseudo neighborhood after one school year HDT.

\subsection{What can we learn from the randomized rollout design?}

So far we have presented and discussed the estimated one-year treatment effects. But we can follow students for a longer period. We mentioned before that our design can be 
interpreted as a randomized rollout design. Table 6 presents the structure of the rollout design. Students are randomly assigned to one of three treated groups, Selection A, B and $\mathrm{C}$ in the table. Selection A receives treatment in 4th grade, Selection B receives treatment in 5th grade, and Selection $\mathrm{C}$ receives treatment in 6th grade. For estimating the onesemester and one-year treatment effects in the Tables 355 of the previous section, we make two kinds of comparisons. To estimate the treatment effect for the 5 th grade experimental sample, we compare Selection B [treatment] and C [control] in the school year directly after randomization. To estimate the one-year treatment effect on the 4 th grade experimental sample, we compare Selection A [treatment] with the combined Selection B\&C [control] in the school year directly after randomization.

Table 6: Structure of the randomized rollout design

\begin{tabular}{lccc}
\hline \hline & 4th grade & 5th grade & 6 th grade \\
\cline { 2 - 4 } Selection A & treated & already treated & already treated \\
Selection B & not treated & treated & already treated \\
Selection C & not treated & not treated & treated \\
\hline \hline
\end{tabular}

One way of exploiting the rollout design is by continuing these comparisons across time. In Figure 3 we continue to follow the 5th grade experimental cohorts into 6th grade. By doing so, we compare two groups that were both treated, but in different periods. We plot the estimated treatment effects by cohort, by semester. We see that the comparison between Selection B and C is changing sign in 6th grade, i.e 3 semesters after randomization. In other words, Selection $\mathrm{C}$ who participates in the tutoring program in 6 th grade, tends to outperform Selection B, the original treatment group of the 5th grade experimental sample, halfway into 6th grade. (Test score data is typically not routinely collected in the second semester of 6th grade.) 
Figure 3: Treatment effects of experimental 5th grade cohorts, in different periods

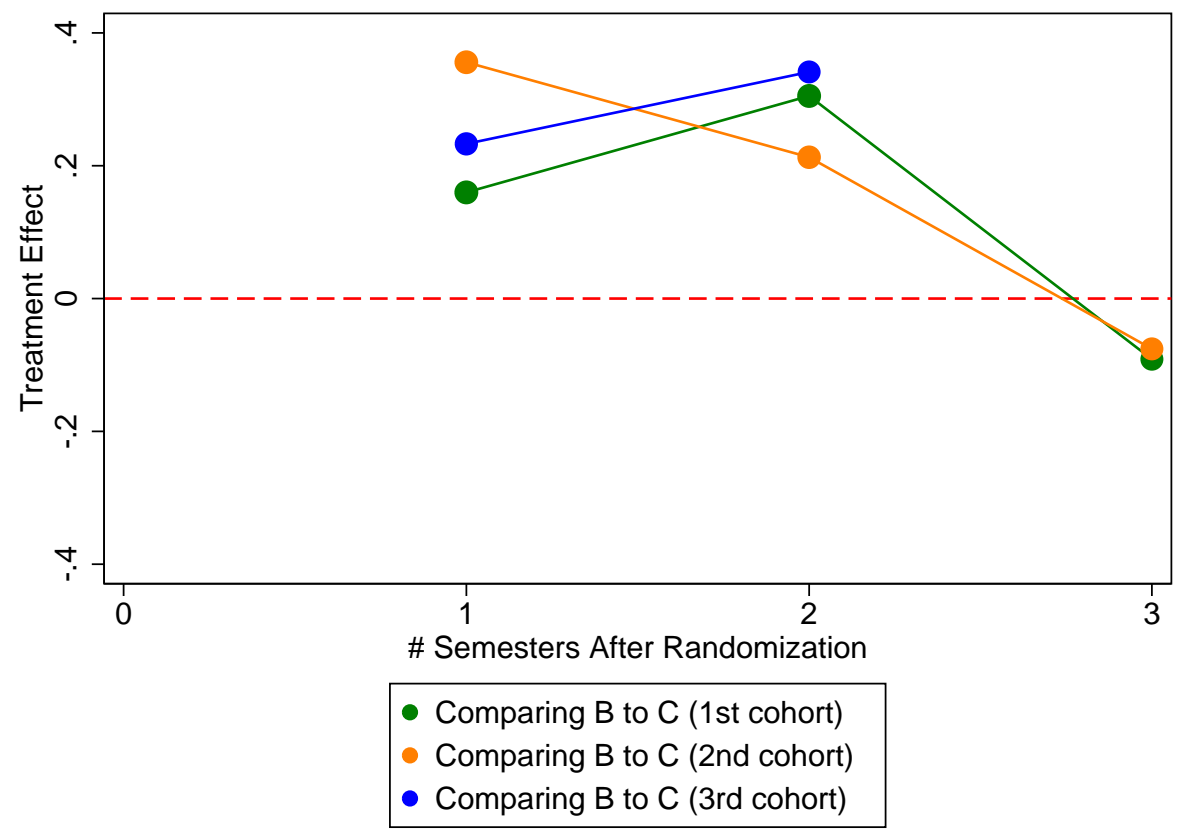

In Figure 4 we continue to compare Selection A with the combined Selection B\&C from 4th to 6 th grade. Note that the initial 4th grade control group, the combined Selection B\&C is the 5 th grade experimental sample. So for the semesters 3 and 4 after randomization, about half of the combined Selection B\&C (i.e. Selection B) received tutoring. Despite the imprecisely estimated parameters we see clearly that the initial 4th grade treatment group [Selection A] tends to lose ground with time, when compared to the combined Selection $\mathrm{B} \& \mathrm{C}$. In the 4 th and 5 th semester the combined selection B\&C has outpaced selection A for the cohorts for which we have data. 
Figure 4: Treatment effects of experimental 4th grade cohorts, in different periods

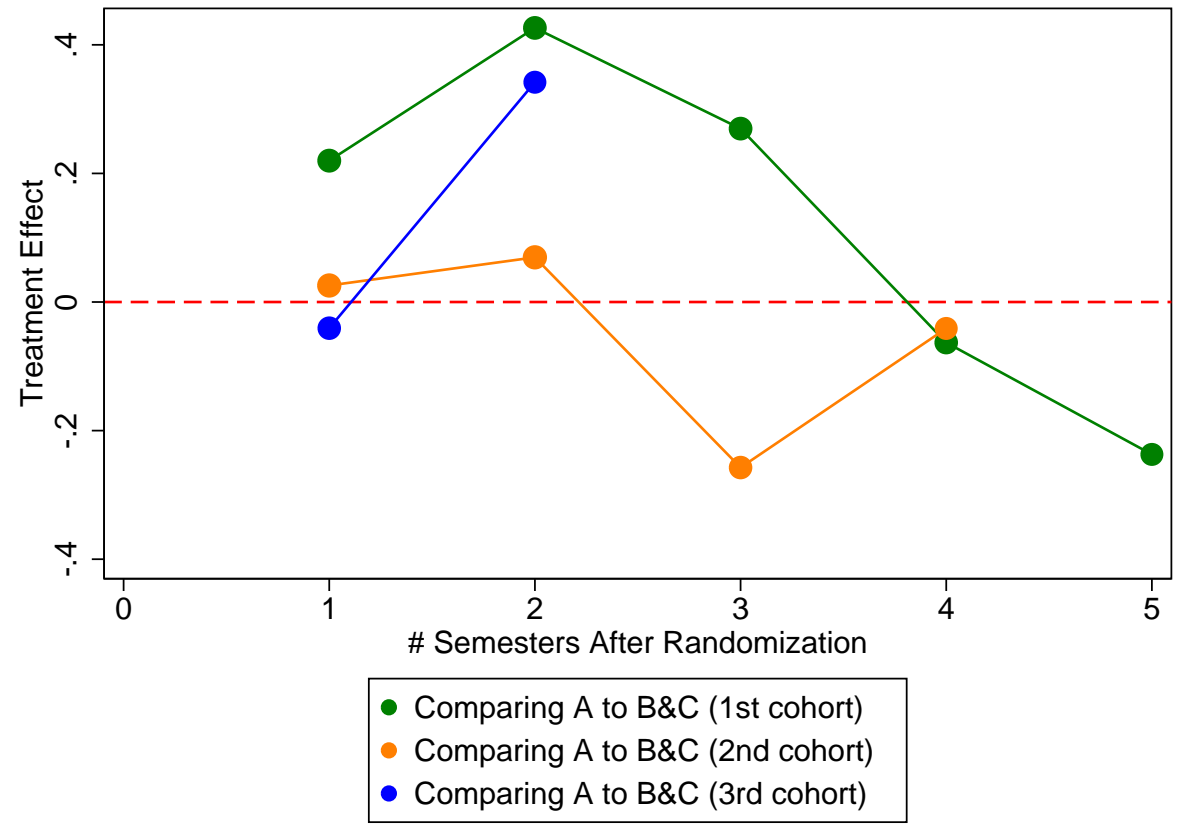

Figure 3 and 4 show that receiving treatment later yields larger treatment effects. This finding indicates that treatment effects decay or that the intervention is more effective in the later grades. Given existing evidence, test score decay in particular seems plausible as most experimental research in education suggests that treatment effects of the same/similar programs decrease with age, not increase. Cascio and Staiger (2012) summarize the literature on randomized field experiments in education and argue that "Decades of research have produced two empirical regularities: interventions in later grades tend to have smaller effects than the same interventions in earlier grades, and the test score impacts of early educational interventions almost universally 'fade out' over time."

Test score decay in the short run however does not rule out longer term effects, in particular, arguably, for interventions with a strong socioemotional component, see e.g. Deming (2009), Chetty, Friedman, and Rockoff (2014) and Sorrenti et al. (2020). Measurable short term gains may go unnoticed in the medium term as they manifest in (skill) domains that 
are not routinely measured. It seems plausible that longer term effects are functions of a belief that performing at a higher level is possible, i.e. being more confident. The setting of the HDT intervention (small groups, stability and individualized instruction) generate repeated experiences of success, which might convince participants they can reach higher. With boosted confidence students might no longer be deterred by difficult math problems. This would allow for building up new skills, which reinforces self-confidence. Such feedback loops might generate effects in the longer term. At this point however we cannot say whether a one year HDT program is sufficient to kick-start this process and further research in this area is needed. We think however that aside from the potential longer term effects, a case can be made for developing lighter touch (tutoring) interventions meant to maintain (and build on) acquired knowledge and skills.

\section{Conclusion}

We show in this paper that HDT can have a meaningful impact on math achievement for low-income primary students in the Netherlands. These results stand out against a backdrop of generally persistent and sizable achievement gaps between high-income and low-income students. The fact that the HDT program examined here was introduced to the Netherlands and built from the ground up in an effort to improve opportunities in a lowincome neighborhood, contributes to the idea that HDT is scalable. Although the program was inspired by Saga Education in the US, and while Saga consulted on the project, it was implemented by professionals who had no prior experience with implementing HDT programs. We find that the HDT intervention can increase math scores by an average of 0.28 national population standard deviations, enough to close the achievement gap in math between low-income and median-income primary students. We also find that high-achievers among the disadvantaged benefit as much as students with lower prior achievement, which 
suggests that also high achieving students from relatively disadvantaged backgrounds can do much better than they already do.

While this research has shown that tutoring programs appear scalable and exportable, one obstacle for further rollout might be their relatively high costs. Setting up a 4/5-days a week model (with daily tutoring) would cost approximately $3,500-4,000 €$ per student per year, depending on the details of implementation ${ }^{26}$ Cost issues have forced service providers to search for alternative HDT models that are currently being implemented and evaluated. For example, Saga Education, the leading HDT provider in the US, is implementing hybrid models that rely on computer aided instruction alongside professional tutors. Programs based on a half-dosage model (2.5 days a week) are also currently being implemented (and RCT-tested) in the Netherlands by The Bridge Learning Interventions. ${ }^{27}$ Related to this is a recent paper by Carlana and La Ferrara (2021), who show that the treatment effects of an online tutoring program during COVID-19 related school lock-downs increase proportionally with the intensity of the intervention.

But even without cutting cost by streamlining the program or by improving targeting, simple cost-benefit calculations suggest that the current HDT intervention might still yield net positive returns. Based on historical test score data The Netherlands Bureau for Economic Policy Analysis (2016) estimates that a 1 standard deviation (combining math and reading) increase in test scores predicts a 5,000€ increase in personal gross income per year. With 40 years of employment, an intervention with a 0.14 (a 0.28 treatment effect on math scores and a 0 treatment effect on reading, average out to a 0.14 unweighted effect on the combined math and reading score) standard deviation treatment effect would yield $40 \times 0.14 \times 5,000=28,000 €$ in additional (personal) income over the life cycle. With a $3 \%$ discount rate, and with 40 years of employment starting at age 24 this means $11,000 €$

\footnotetext{
${ }^{26}$ Tutors typically earn a minimum wage or slightly above that. The site director, responsible for oversight, day-to-day management and communication with the schools, earns about twice that amount.

${ }^{27}$ https://www.tbli.nl/en/home-english/
} 
in present value terms. For the Saga Education HDT program in the US, Guryan et. al. (2021) reach qualitatively similar conclusions.

We see a number of areas for further research in this area. By the nature of our experimental design, we are not able to use this data to study the longer term effect of this program. We intend to set up new HDT experiments to measure such longer term impacts. Second, as the HDT model has an explicit socioemotional/noncognitive component, we see opportunities to measure effects on non-cognitive functioning explicitly. One way forward might be to use question/item level data, to disentangle cognitive and noncognitive factors from the performance on a single test, as in Borghans and Schils (2018). 


\section{A Baseline summary tables}

Table 7: Baseline summary statistics for the 5th grade experimental sample, pooled across cohorts

\begin{tabular}{lccccc}
\hline & $\begin{array}{c}(1) \\
\text { semester }\end{array}$ & $\begin{array}{c}(2) \\
\text { treatment }\end{array}$ & $\begin{array}{c}(3) \\
\text { control }\end{array}$ & $\begin{array}{c}(4) \\
\text { difference }\end{array}$ & $\begin{array}{c}(5) \\
\text { p-value }\end{array}$ \\
\cline { 2 - 5 } Boy & & & & & \\
Boy & 1 & 0.48 & 0.52 & -0.04 & 0.55 \\
Weighted student & 2 & 0.48 & 0.52 & -0.04 & 0.55 \\
Weighted student & 1 & 0.35 & 0.35 & -0.00 & 0.98 \\
Math score observed & 2 & 0.35 & 0.35 & -0.00 & 0.98 \\
Math score observed & 1 & 0.95 & 0.92 & 0.04 & 0.22 \\
Standardized math score & 2 & 0.92 & 0.93 & -0.00 & 0.94 \\
Standardized math score & 1 & -0.38 & -0.30 & -0.08 & 0.52 \\
Reading score observed & 2 & -0.40 & -0.34 & -0.06 & 0.62 \\
Reading score observed & 1 & 0.96 & 0.91 & 0.05 & 0.15 \\
Standardized reading score & 1 & 0.74 & 0.73 & 0.01 & 0.80 \\
Standardized reading score & 2 & -0.48 & -0.36 & -0.13 & 0.32 \\
Math speed test score observed & 1 & 0.67 & -0.37 & -0.24 & 0.14 \\
Math speed test score observed & 2 & 0.74 & 0.63 & 0.04 & 0.07 \\
Raw math speed test score & 1 & 101.30 & 103.13 & -1.83 & 0.51 \\
Raw math speed test score & 2 & 105.77 & 107.94 & -2.16 & 0.46 \\
\hline
\end{tabular}

Notes. Baseline summary statistics. Column 1 indicates the semester of the school year prior to randomization. A stratum fixed effects model is used to estimate the quantities reported in the columns 2-5. 
Table 8: Baseline summary statistics for the 4th grade experimental sample, pooled across cohorts

\begin{tabular}{lccccc}
\hline & $\begin{array}{c}(1) \\
\text { semester }\end{array}$ & $\begin{array}{c}(2) \\
\text { treatment }\end{array}$ & $\begin{array}{c}(3) \\
\text { control }\end{array}$ & $\begin{array}{c}(4) \\
\text { difference }\end{array}$ & $\begin{array}{c}(5) \\
\text { p-value }\end{array}$ \\
\cline { 2 - 5 } Boy & 1 & 0.57 & 0.47 & 0.10 & 0.25 \\
Boy & 2 & 0.57 & 0.47 & 0.10 & 0.25 \\
Weighted student & 1 & 0.30 & 0.38 & -0.07 & 0.37 \\
Weighted student & 2 & 0.30 & 0.38 & -0.07 & 0.37 \\
Math score observed & 1 & 0.98 & 0.90 & 0.08 & 0.03 \\
Math score observed & 2 & 0.98 & 0.92 & 0.07 & 0.04 \\
Standardized math score & 1 & -0.38 & -0.31 & -0.07 & 0.71 \\
Standardized math score & 2 & -0.34 & -0.56 & 0.22 & 0.31 \\
Reading score observed & 1 & 0.97 & 0.92 & 0.05 & 0.14 \\
Reading score observed & 2 & 0.61 & 0.54 & 0.08 & 0.06 \\
Standardized reading score & 1 & -0.39 & -0.41 & 0.02 & 0.88 \\
Standardized reading score & 2 & -0.42 & -0.70 & 0.29 & 0.14 \\
Math speed test score observed & 1 & 0.34 & 0.31 & 0.04 & 0.26 \\
Math speed test score observed & 2 & 0.44 & 0.44 & 0.01 & 0.78 \\
Raw math speed test score & 1 & 104.83 & 96.86 & 7.97 & 0.23 \\
Raw math speed test score & 2 & 106.85 & 99.84 & 7.01 & 0.26 \\
\hline
\end{tabular}

Notes. Baseline summary statistics. Column 1 indicates the semester of the school year prior to randomization. A stratum fixed effects model is used to estimate the quantities reported in the columns $2-5$. 


\section{B Breakout results by cohort}

Table 9: Treatment effects on math scores for 5th grade experimental sample, measured in national population standard deviation units

\begin{tabular}{|c|c|c|c|c|c|c|}
\hline & $\begin{array}{c}(1) \\
1 \text { st } \\
\text { semester }\end{array}$ & $\begin{array}{c}(2) \\
\text { 2nd } \\
\text { semester }\end{array}$ & $\begin{array}{c}(3) \\
\text { 3rd } \\
\text { semester }\end{array}$ & $\begin{array}{c}(4) \\
4 \text { th } \\
\text { semester }\end{array}$ & $\begin{array}{c}(5) \\
5 \text { th } \\
\text { semester }\end{array}$ & $\begin{array}{c}(6) \\
6 t h \\
\text { semester }\end{array}$ \\
\hline 5 th grade cohort 1 & $\begin{array}{c}0.16 \\
(0.10) \\
{[101]} \\
<97> \\
|94|\end{array}$ & $\begin{array}{c}0.31 * * * \\
(0.09) \\
{[101]} \\
<97> \\
|94|\end{array}$ & $\begin{array}{c}-0.09 \\
(0.14) \\
{[101]} \\
<89> \\
|86|\end{array}$ & & & \\
\hline 5 th grade cohort 2 & $\begin{array}{c}0.36^{* * *} \\
(0.10) \\
{[89]} \\
<86> \\
|82|\end{array}$ & $\begin{array}{c}0.21^{*} \\
(0.11) \\
{[89]} \\
<84> \\
|80|\end{array}$ & $\begin{array}{c}-0.08 \\
(0.11) \\
{[89]} \\
<80> \\
|76|\end{array}$ & & & \\
\hline 5 th grade cohort 3 & $\begin{array}{c}0.23 \\
(0.16) \\
{[75]} \\
<72> \\
|70|\end{array}$ & $\begin{array}{c}0.34 * * * \\
(0.10) \\
{[75]} \\
<70> \\
|68|\end{array}$ & & & & \\
\hline pooled 5 th grade cohort & $\begin{array}{c}0.25 * * * \\
(0.07) \\
{[265]} \\
<255> \\
|246|\end{array}$ & $\begin{array}{c}0.28 * * * \\
(0.06) \\
{[265]} \\
<251> \\
|242|\end{array}$ & & & & \\
\hline
\end{tabular}

Notes. $* * *, * *, *$ indicate statistical significance at the 1,5 , and $10 \%$ level. Point estimates measured in national population standard deviations. Heteroskedasticity robust standard errors in parentheses. All regressions include sampling block (or stratum) fixed effects (the level at which randomization was done) and baseline test score values. The total size of the experimental sample between [..], the size of the sample used to produce the estimates between $\langle.$.$\rangle , the size of the sample which has observed baseline test scores between |.$.$| .$ Missing baseline test scores are set to zero, and a dummy variable is included that is 1 for observations for which baseline tests are missing. 
Table 10: Treatment effects on math scores for 4th grade experimental sample, measured in national population standard deviation units

\begin{tabular}{|c|c|c|c|c|c|c|}
\hline & $\begin{array}{c}(1) \\
1 \text { st } \\
\text { semester }\end{array}$ & $\begin{array}{c}(2) \\
\text { 2nd } \\
\text { semester }\end{array}$ & $\begin{array}{c}(3) \\
\text { 3rd } \\
\text { semester }\end{array}$ & $\begin{array}{c}(4) \\
4 \text { th } \\
\text { semester }\end{array}$ & $\begin{array}{c}(5) \\
5 \text { th } \\
\text { semester }\end{array}$ & $\begin{array}{c}(6) \\
6 t h \\
\text { semester }\end{array}$ \\
\hline 4th grade cohort 1 & $\begin{array}{c}0.22 \\
(0.14) \\
{[96]} \\
<91> \\
|85|\end{array}$ & $\begin{array}{c}0.43 * * * \\
(0.15) \\
{[96]} \\
<90> \\
|84|\end{array}$ & $\begin{array}{c}0.27 \\
(0.19) \\
{[96]} \\
<90> \\
|84|\end{array}$ & $\begin{array}{c}-0.06 \\
(0.12) \\
{[96]} \\
<88> \\
|83|\end{array}$ & $\begin{array}{c}-0.24^{*} \\
(0.14) \\
{[96]} \\
<83> \\
|78|\end{array}$ & \\
\hline 4 th grade cohort 2 & $\begin{array}{c}0.03 \\
(0.20) \\
{[93]} \\
<88> \\
|84|\end{array}$ & $\begin{array}{c}0.07 \\
(0.29) \\
{[93]} \\
<88> \\
|84|\end{array}$ & $\begin{array}{c}-0.26 \\
(0.19) \\
{[93]} \\
<82> \\
|78|\end{array}$ & $\begin{array}{c}-0.04 \\
(0.17) \\
{[93]} \\
<78> \\
|74|\end{array}$ & & \\
\hline 4 th grade cohort 3 & $\begin{array}{c}-0.04 \\
(0.21) \\
{[44]} \\
<43> \\
|42|\end{array}$ & $\begin{array}{c}0.34 \\
(0.21) \\
{[44]} \\
<41> \\
|40|\end{array}$ & & & & \\
\hline pooled 4 th grade cohort & $\begin{array}{c}0.08 \\
(0.11) \\
{[233]} \\
<222> \\
|211|\end{array}$ & $\begin{array}{c}0.26^{*} \\
(0.15) \\
{[233]} \\
<219> \\
|208|\end{array}$ & & & & \\
\hline
\end{tabular}

Notes. $* * *, * *, *$ indicate statistical significance at the 1,5 , and $10 \%$ level. Point estimates measured in national population standard deviation units. Heteroskedasticity robust standard errors in parentheses. All regressions include sampling block (or stratum) fixed effects (the level at which randomization was done) and baseline test score values. The total size of the experimental sample between [..], the size of the sample used to produce the estimates between $\langle.$.$\rangle , the size of the sample which has observed baseline test scores$ between $|.$.$| . Missing baseline test scores are set to zero, and a dummy variable is included$ that is 1 for observations for which baseline tests are missing. 
Table 11: Treatment effects on reading comprehension scores for 5th grade experimental sample, measured in national population standard deviation units

\begin{tabular}{|c|c|c|c|c|c|c|}
\hline & $\begin{array}{c}(1) \\
1 \text { st } \\
\text { semester }\end{array}$ & $\begin{array}{c}(2) \\
\text { 2nd } \\
\text { semester }\end{array}$ & $\begin{array}{c}(3) \\
\text { 3rd } \\
\text { semester }\end{array}$ & $\begin{array}{c}(4) \\
4 \text { th } \\
\text { semester }\end{array}$ & $\begin{array}{c}(5) \\
5 \text { th } \\
\text { semester }\end{array}$ & $\begin{array}{c}(6) \\
6 \text { th } \\
\text { semester }\end{array}$ \\
\hline 5 th grade cohort 1 & $\begin{array}{c}-0.12 \\
(0.15) \\
{[101]} \\
<98> \\
|95|\end{array}$ & $\begin{array}{c}-0.04 \\
(0.17) \\
{[101]} \\
<75> \\
|73|\end{array}$ & $\begin{array}{c}0.20 \\
(0.19) \\
{[101]} \\
<90> \\
|87|\end{array}$ & & & \\
\hline 5 th grade cohort 2 & $\begin{array}{c}-0.00 \\
(0.17) \\
{[89]} \\
<86> \\
|82|\end{array}$ & $\begin{array}{c}-0.04 \\
(0.19) \\
{[89]} \\
<78> \\
|75|\end{array}$ & $\begin{array}{c}-0.06 \\
(0.20) \\
{[89]} \\
<79> \\
|75|\end{array}$ & & & \\
\hline 5 th grade cohort 3 & $\begin{array}{c}-0.10 \\
(0.19) \\
{[75]} \\
<72> \\
|70|\end{array}$ & $\begin{array}{c}-0.10 \\
(0.16) \\
{[75]} \\
<69> \\
|67|\end{array}$ & & & & \\
\hline pooled 5th grade cohort & $\begin{array}{c}-0.07 \\
(0.10) \\
{[265]} \\
<256> \\
|247|\end{array}$ & $\begin{array}{c}-0.06 \\
(0.11) \\
{[265]} \\
<222> \\
|215|\end{array}$ & & & & \\
\hline
\end{tabular}

Notes. $* * *, * *, *$ indicate statistical significance at the 1,5 , and $10 \%$ level. Point estimates measured in national population standard deviation units. Heteroskedasticity robust standard errors in parentheses. All regressions include sampling block (or stratum) fixed effects (the level at which randomization was done) and baseline test score values. The total size of the experimental sample between [..], the size of the sample used to produce the estimates between $\langle.$.$\rangle , the size of the sample which has observed baseline test scores$ between |..|. Missing baseline test scores are set to zero, and a dummy variable is included that is 1 for observations for which baseline tests are missing. 
Table 12: Treatment effects on reading comprehension scores for 4th grade experimental sample, measured in national population standard deviation units

\begin{tabular}{|c|c|c|c|c|c|c|}
\hline & $\begin{array}{c}(1) \\
1 \text { st } \\
\text { semester }\end{array}$ & $\begin{array}{c}(2) \\
\text { 2nd } \\
\text { semester }\end{array}$ & $\begin{array}{c}(3) \\
\text { 3rd } \\
\text { semester }\end{array}$ & $\begin{array}{c}(4) \\
4 \text { th } \\
\text { semester }\end{array}$ & $\begin{array}{c}(5) \\
5 \text { th } \\
\text { semester }\end{array}$ & $\begin{array}{c}(6) \\
6 t h \\
\text { semester }\end{array}$ \\
\hline 4 th grade cohort 1 & $\begin{array}{c}0.01 \\
(0.18) \\
{[96]} \\
<92> \\
|87|\end{array}$ & $\begin{array}{c}0.03 \\
(0.15) \\
{[96]} \\
<91> \\
|86|\end{array}$ & $\begin{array}{c}-0.03 \\
(0.21) \\
{[96]} \\
<90> \\
|85|\end{array}$ & $\begin{array}{c}-0.09 \\
(0.20) \\
{[96]} \\
<82> \\
|77|\end{array}$ & $\begin{array}{c}-0.04 \\
(0.21) \\
{[96]} \\
<82> \\
|77|\end{array}$ & \\
\hline 4 th grade cohort 2 & $\begin{array}{c}-0.16 \\
(0.16) \\
{[93]} \\
<89> \\
|84|\end{array}$ & $\begin{array}{c}-0.20 \\
(0.23) \\
{[93]} \\
<88> \\
|83|\end{array}$ & $\begin{array}{c}-0.31 \\
(0.22) \\
{[93]} \\
<82> \\
|77|\end{array}$ & $\begin{array}{c}-0.36 \\
(0.30) \\
{[93]} \\
<79> \\
|74|\end{array}$ & & \\
\hline 4 th grade cohort 3 & $\begin{array}{c}-0.08 \\
(0.20) \\
{[44]} \\
<43> \\
|42|\end{array}$ & $\begin{array}{c}-0.11 \\
(0.25) \\
{[44]} \\
<43> \\
|42|\end{array}$ & & & & \\
\hline pooled 4 th grade cohort & $\begin{array}{c}-0.07 \\
(0.11) \\
{[233]} \\
<224> \\
|213|\end{array}$ & $\begin{array}{c}-0.09 \\
(0.12) \\
{[233]} \\
<222> \\
|211|\end{array}$ & & & & \\
\hline
\end{tabular}

Notes. $* * *, * *, *$ indicate statistical significance at the 1,5 , and $10 \%$ level. Point estimates measured in national population standard deviation units. Heteroskedasticity robust standard errors in parentheses. All regressions include sampling block (or stratum) fixed effects (the level at which randomization was done) and baseline test score values. The total size of the experimental sample between [..], the size of the sample used in to produce the estimates between $\langle.$.$\rangle , the size of the sample which has observed baseline test scores$ between |..|. Missing baseline test scores are set to zero, and a dummy variable is included that is 1 for observations for which baseline tests are missing. 


\section{Treatment effects measured in control group stan- dard deviation units}

Table 13: Treatment effects on math scores, measured in control group standard deviation units

\begin{tabular}{|c|c|c|}
\hline & $\begin{array}{c}(1) \\
\text { half-year treatment effect }\end{array}$ & $\begin{array}{c}(2) \\
\text { one year treatment effect }\end{array}$ \\
\hline pooled 5th grade cohort & $\begin{array}{c}0.22^{* * *} \\
(0.06) \\
{[265]} \\
<255> \\
|246|\end{array}$ & $\begin{array}{c}0.25 * * * \\
(0.05) \\
{[265]} \\
<251> \\
|242|\end{array}$ \\
\hline pooled 4 th grade cohort & $\begin{array}{c}0.08 \\
(0.10) \\
{[233]} \\
<222> \\
|211|\end{array}$ & $\begin{array}{c}0.24^{*} \\
(0.13) \\
{[233]} \\
<219> \\
|208|\end{array}$ \\
\hline
\end{tabular}

Notes. $* * *, * *, *$ indicate statistical significance at the 1,5 , and $10 \%$ level. Point estimates measured in control group standard deviation units. Heteroskedasticity robust standard errors in parentheses. All regressions include sampling block (or stratum) fixed effects (the level at which randomization was done) and baseline test score values. The total size of the experimental sample between [..], the size of the sample used to produce the estimates between $\langle.$.$\rangle , the size of the sample which has observed baseline test scores between$ |..|. Missing baseline test scores are set to zero and a dummy variable is included in the regression model that is 1 for observations for which baseline tests are missing. 
Table 14: Treatment effects on reading comprehension scores, measured in control group standard deviation units

(1)

half-year treatment effect
(2)

one year treatment effect

pooled 5th grade cohort

$\begin{array}{cc}-0.07 & -0.05 \\ (0.09) & (0.10) \\ {[265]} & {[265]} \\ <256> & <222> \\ |247| & |215|\end{array}$

pooled 4th grade cohort

Notes. $* * *, * *, *$ indicate statistical significance at the 1,5 , and $10 \%$ level. Point estimates measured in control group standard deviation units. Heteroskedasticity robust standard errors in parentheses. All regressions include sampling block (or stratum) fixed effects (the level at which randomization was done) and baseline test score values. The total size of the experimental sample between [..], the size of the sample used to produce the estimates between $\langle.$.$\rangle , the size of the sample which has observed baseline test scores between |.$.$| .$ Missing baseline test scores are set to zero, and a dummy variable is included that is 1 for observations for which baseline tests are missing. 


\section{Heterogeneity}

Figure 5: Scatter diagrams of baseline to endline math gain scores, against baseline math scores in percentiles. Top, middle and bottom figures are for the 2015/16, 2016/17 and 2017/18 5th grade experimental cohorts respectively. Local linear polynomial (with bandwidth 10) are used to fit the data.
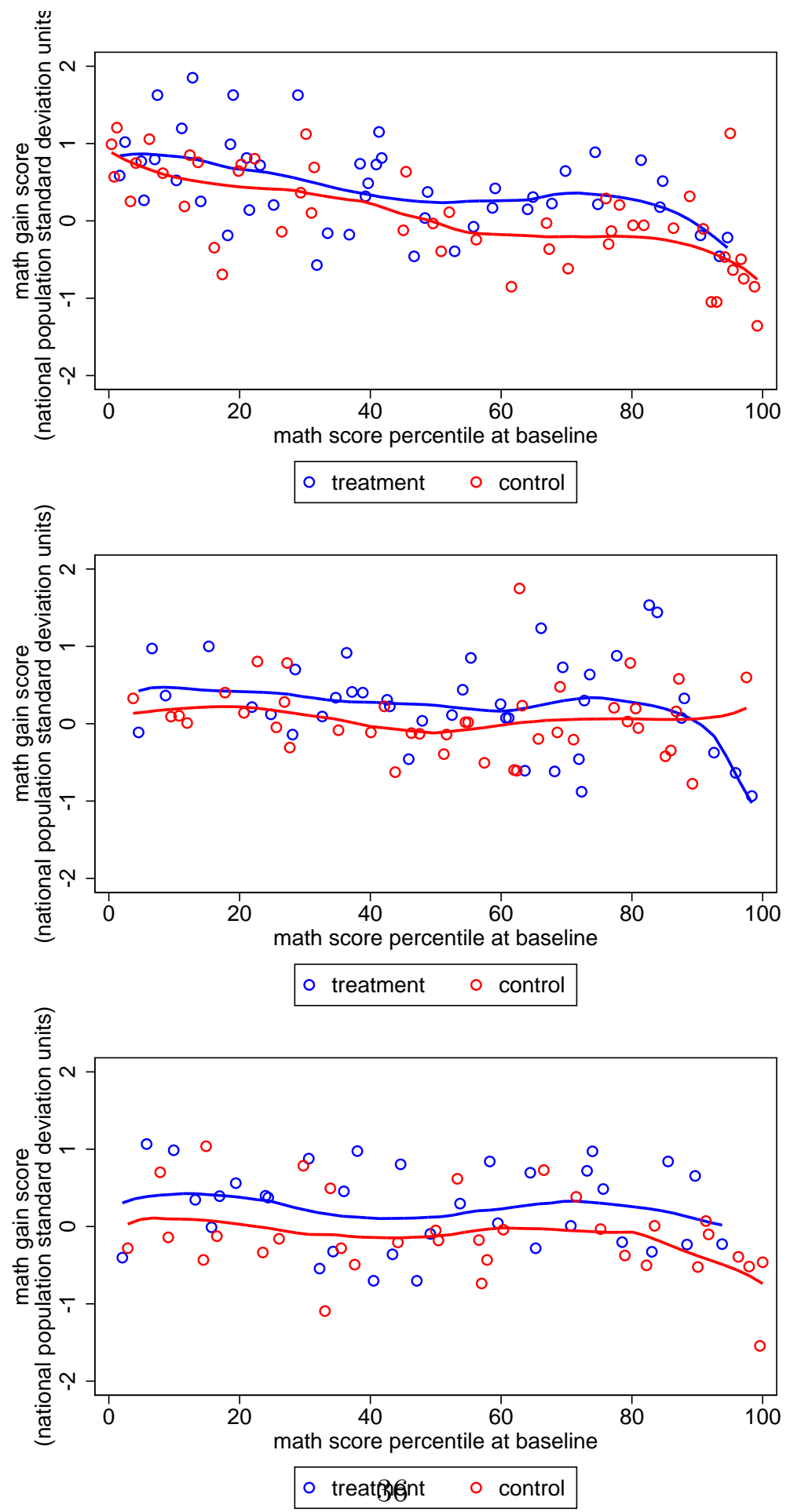


\section{E Validity tests}

\section{E.1 Testing for random attrition}

Nonrandom attrition is a potential threat to internal validity. We test whether a missing test score depends on treatment assignment in Table 15 and 16 panel A. In Table 15 and 16 panel B we test whether a missing test score depends on the baseline test score in the same way between treatment and control. We operationalize the latter by regressing an indicator for missing outcome test score data on the baseline score, an indicator for the treatment group, and an interaction between the two. We find that baseline scores are somewhat predictive of sample attrition, but we do not measure significant differences between treatment and control. The tables do not provide evidence for nonrandom attrition. 
Table 15: Tests for random attrition (absence of outcome math scores)

\begin{tabular}{|c|c|c|}
\hline & $\begin{array}{c}(1) \\
\text { half-year treatment effect }\end{array}$ & $\begin{array}{c}(2) \\
\text { one year treatment effect }\end{array}$ \\
\hline \multicolumn{3}{|l|}{ A: Simple comparison } \\
\hline \multirow[t]{3}{*}{ Treatment } & -0.034 & -0.019 \\
\hline & $(0.023)$ & $(0.026)$ \\
\hline & {$[265]$} & {$[265]$} \\
\hline \multicolumn{3}{|c|}{ B: Interacted with baseline outcome } \\
\hline \multirow[t]{2}{*}{ Treatment } & -0.019 & -0.001 \\
\hline & $(0.018)$ & $(0.022)$ \\
\hline \multirow[t]{2}{*}{ Baseline outcome } & $-0.011^{*}$ & $-0.019 * *$ \\
\hline & $(0.007)$ & $(0.009)$ \\
\hline \multirow[t]{3}{*}{ Treatment $\times$ Baseline outcome } & 0.006 & 0.008 \\
\hline & $(0.010)$ & $(0.014)$ \\
\hline & {$[252]$} & {$[252]$} \\
\hline
\end{tabular}

Notes. ${ }^{* * *},{ }^{* *}, *$ indicate statistical significance at the 1,5 , and $10 \%$ level. Heteroskedasticity robust standard errors in parentheses. All regressions include sampling block (or stratum) fixed effects (the level at which randomization was done). The sample size used in estimation between $[.$.$] .$ 
Table 16: Tests for random attrition (absence of outcome reading scores)

(1)

\section{A: Simple comparison}

Treatment

$-0.011$

$-0.024$

$(0.023)$

[265]

[265]

\section{B: Interacted with baseline outcome}

Treatment

$-0.007$

$-0.015$

Baseline outcome

$-0.012$

$-0.030^{*}$

$(0.009)$

Treatment $\times$ Baseline outcome

$-0.003$

$-0.004$

(0.019)

$[253]$

$[253]$

Notes. $* * *, * *, *$ indicate statistical significance at the 1,5 , and $10 \%$ level. Heteroskedasticity robust standard errors in parentheses. All regressions include sampling block (or stratum) fixed effects (the level at which randomization was done). The sample size used in estimation between [..].

\section{F Adjustment for less than perfect reliability}

For Figure 2 we want to estimate $E\left[s^{*} \mid p_{k}\right]$, where $s^{*}$ is the standardized true math score and $p_{k}$ are parental income percentiles. Suppose further that the underlying observed math score $y$ measures the true math score $y^{*}$ with random noise $e$ :

$$
y=y^{*}+e
$$

with $E\left[e \mid y^{*}\right]=0$.

For Figure we estimate $E\left[\frac{y-E[y]}{S D(y) \sqrt{\rho_{y}}} \mid p_{k}\right]$, which we show below equals the quantity of 
interest $E\left[s^{*} \mid p_{k}\right]$ :

$$
\begin{aligned}
E\left[s^{*} \mid p_{k}\right] & =E\left[\frac{y^{*}-E\left[y^{*}\right]}{S D\left(y^{*}\right)} \mid p_{k}\right] \\
& =E\left[\frac{y-E[y]}{S D(y) \frac{S D\left(y^{*}\right)}{S D(y)}} \mid p_{k}\right] \\
& =E\left[\frac{y-E[y]}{S D(y) \sqrt{\rho_{y}}} \mid p_{k}\right]
\end{aligned}
$$

where $\rho_{y}$ is the reliability of test score $y$. The quantity $\frac{y-E[y]}{S D(y) \sqrt{\rho_{y}}}$ is a the standardized observed math score, with an inflated variance. Reliabilities are not observed in the data. We use reliability rates reported by the test developer. Generally, reliabilities for these tests are high: 0.90 for the separate math and language components and 0.95 for the full test (Cito 2013).

\section{G Parental income and some dimensions of govern- ment support}

Figure 6 shows that low income students are more likely to be weighted students (for which schools receive additional state funding) and more likely to receive rent support. The figure also shows that the lowest income percentile categories are a special group, mixing low income earners as well as others with higher earning potential, e.g. entrepreneurs with occasional low income spells. As this is beyond the scope of this paper, we have not specifically studied this group in more detail. 
Figure 6: Relationship between parental income of primary school 6th graders and fraction of "weighted" students [top panel] and fraction renters with rent support [bottom panel]
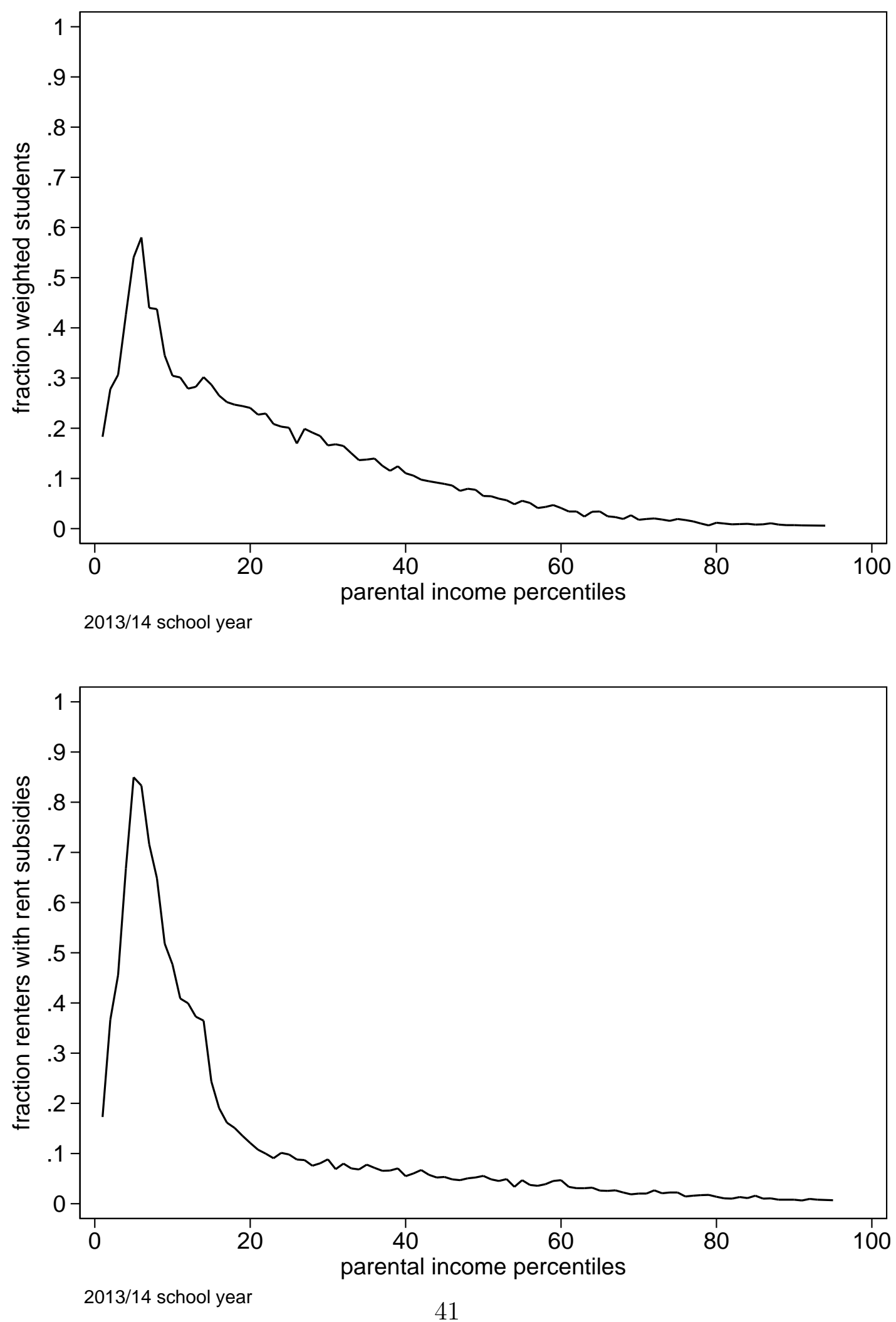


\section{H Full author lists for abbreviated citations}

- Guryan et al. (2021) for Guryan, Ludwig, Bhatt, Cook, Davis, Dodge, Farkas, Fryer Jr., Mayer, Pollack, and Steinberg (2021)

- Sorrenti et al. (2020) for Sorrenti, Zölitz, Ribeaud, and Eisner (2020)

- Pellegrini et al. (2021) for Pellegrini, Lake, Neitzel, and Slavin (2021)

- Kosse et al. (2020) for Kosse, Deckers, Pinger, Schildberg-Hörisch, and Falk (2020)

- De Ree et al. (2018) for De Ree, Muralidharan, Pradhan, and Rogers (2018)

- Davis et al. (2017) for Davis, Guryan, Hallberg, and Ludwig (2017)

- Cook et al. (2014) Cook, Dodge, Farkas, Jr., Guryan, Ludwig, Mayer, Pollack, and Steinberg (2014) 


\section{References}

Alesina, A., And G.-M. Angeletos (2005): "Fairness and Redistribution," American Economic Review, 95(4).

Alesina, A., and E. L. Glaeser (2005): Fighting Poverty in the US and Europe: A World of Difference.

Andrabi, T., B. Daniels, And J. Das (2020): "Human Capital Accumulation and Disasters: Evidence from the Pakistan Earthquake of 2005," RISE working paper series, $(20 / 039)$.

BLOOM, B. S. (1984): "The 2 sigma problem: The search for methods of group instruction as effective as one-on-one tutoring," Educational Observer, 13(6).

Borghans, L., R. Diris, and T. Schils (2018): "Sociale ongelijkheid in het onderwijs is hardnekkig," Economisch Statistische Berichten (ESB), 103(4768).

Borghans, L., And T. Schils (2018): "Decomposing achievement test scores into measures of cognitive and noncognitive skills," Working paper.

Carlana, M., and E. La Ferrara (2021): "Apart but Connected: Online Tutoring and Student Outcomes during the COVID-19 Pandemic," HKS Faculty Research Working Paper Series, 21(001).

Cascio, E. U., and D. O. Staiger (2012): "Knowledge, tests, and fadeout in educational interventions," NBER, (18038).

Chetty, R., J. N. Friedman, and J. E. Rockoff (2014): "Measuring the Impacts of Teachers II: Teacher Value-Added and Student Outcomes in Adulthood," American Economic Review, 104(9). 
Ciтo (2013): "Terugblik en resultaten 2013 eindtoets Basisonderwijs groep 8," Report.

Cook, P. J., K. Dodge, G. Farkas, R. G. F. JR., J. Guryan, J. Ludwig, S. Mayer, H. Pollack, And L. Steinberg (2014): "The (surprising) efficacy of academic and behavioral intervention with disadvantaged youth: Results from a randomized experiment in Chicago," NBER, (19862).

Davis, J. M., J. Guryan, K. Hallberg, and J. Ludwig (2017): "The Economics of Scale-Up," NBER working paper, (23925).

De Ree, J., K. Muralidharan, M. Pradhan, and H. Rogers (2018): "Double for Nothing? Experimental Evidence on an Unconditional Teacher Salary Increase in Indonesia," The Quarterly Journal of Economics.

Deming, D. (2009): "Early Childhood Intervention and Life-Cycle Skill Development: Evidence from Head Start," American Economic Journal: Applied Economics, 1(3).

Duncan, G. J., K. Magnuson, and E. Votruba-Drza (2017): "Moving Beyond Correlations in Assessing the Consequences of Poverty," Annual Review of Psychology, 68.

Dutch Inspectorate of Education (2019): "De Staat van het Onderwijs 2019," Report.

Engzell, P., A. Frey, and M. Verhagen (2020): "Learning inequality during the COVID-19 pandemic," working paper.

Fryer JR., R. G. (2014): "Injecting Charter School Best Practices into Traditional PublicSchools:Evidence From Field Experiments," The Quarterly Journal of Economics, $129(3)$. 
Guryan, J., J. Ludwig, M. P. Bhatt, P. J. Cook, J. M. Davis, K. Dodge, G. Farkas, R. G. Fryer JR., S. Mayer, H. Pollack, and L. Steinberg (2021): "Not Too Late: Improving Academic Outcomes Among Adolescents," NBER working paper, (28531).

Heckman, J. J., J. Stixrud, and S. Urzua (2006): "The Effects of Cognitive and Noncognitive Abilities on Labor Market Outcomes and Social Behavior," Journal of Labor Economics, 24(3).

JaCkson, C. K. (2018): "Does School Spending Matter? The New Literature on an Old Question," NBER working paper series, (25368).

Jackson, C. K., R. C. Johnson, and C. Persico (2016): "The Effects of School Spending on Educational and Economic Outcomes: Evidence from School Finance Reforms," The Quarterly Journal of Economics, 131(1).

Jacob, B. A., And L. Lefgren (2004): "The Impact of Teacher Training on Student Achievement: Quasi-Experimental Evidence from School Reform Efforts in Chicago," Journal of Human Resources, 39(1).

Kosse, F., T. Deckers, P. Pinger, H. Schildberg-Hörisch, and A. Falk (2020): "The formation of prosociality: Causal evidence on the role of social environment," Journal of Political Economy, 128(2).

Kraft, M. A. (2015): "How to Make Additional Time Matter: Integrating Individualized Tutorials into an Extended Day," Education Finance and Policy, 10(1).

(2020): "Interpreting Effect Sizes of Education Interventions," Educational Researcher, 49(4), 241-253. 
LadD, H. F., And E. B. Fiske (2011): "Weighted student funding in the Netherlands: A model for the U.S.?," Journal of Policy Analysis and Finance.

Michelmore, K., And S. Dynarski (2017): "The Gap Within the Gap: Using Longitudinal Data to Understand Income Differences in Educational Outcomes," AERA Open, $3(1)$

Nickow, A., P. Oreopoulos, And V. Quan (2020): "The Impressive Effects of Tutoring on PreK-12 Learning: A systematic Review and Meta-Analysis of the Experimental Evidence," NBER working paper series, (27476).

Pellegrini, M., C. Lake, A. Neitzel, and R. E. Slavin (2021): "Effective Programs in Elementary Mathematics: A Meta-Analysis," AERA Open, 7(1).

Reardon, S. (2011): "The Widening Academic Achievement Gap Between the Rich and the Poor: New Evidence and Possible Explanations," Chapter in book.

Sorrenti, G., U. Zölitz, D. Ribeaud, and M. Eisner (2020): "The Causal Impact of Socio-Emotional Skills Training on Educational Success," IZA DP, (13087).

The Netherlands Bureau for Economic Policy Analysis (2016): "Kansrijk onderwijsbeleid," . 